\title{
The Operationalisation of Safety Culture for the Malaysian Construction Organisations
}

\author{
Faridah Ismail (Corresponding author) \\ Faculty of Architecture, Planning \& Surveying \\ Universiti Teknologi MARA, MALAYSIA \\ Tel: 60-3-5521-1509Ｅ-mail: farid346@salam.uitm.edu.my \\ Ahmad Ezanee Hashim \\ Faculty of Architecture, Planning \& Surveying \\ Universiti Teknologi MARA, MALAYSIA \\ Tel: 60-3-5544-4325 E-mail: ezanee54@yahoo.com \\ Razidah Ismail \\ Faculty of Computer \& Mathematical Sciences \\ Universiti Teknologi MARA, MALAYSIA \\ Tel: 60-3-5543-5428Ｅ-mail: razidah @tmsk.uitm.edu.my \\ Muhd. Zaimi Abdul Majid \\ Faculty of Civil Engineering \\ Universiti Teknologi Malaysia, MALAYSIA \\ Tel: 60-7-5537-843 E-mail: mzaimi@utm.my
}

\begin{abstract}
This paper presents the operationalisation of safety culture for the Malaysian construction organisations. Operationalisation is the process of converting a concept into a measure. This measure can be a variable, constant or scale depending upon the situation. Hence, operationalisation will enable the concept to be uniformly understood as there is no measurement has yet been established to enable the industry players to gauge their current state of safety culture. Both qualitative and quantitative methods have unique potential for assessment and a combination of both methods is beneficial towards a comprehensive understanding of safety culture. A mixed methodology is adopted; the preliminary survey and the main survey as an instrument to measure safety culture were developed. The findings revealed that safety culture comprised of the psychological, behavioural and the situational factors' characteristics created by the senior management.
\end{abstract}

Keywords: Operationalisation, Safety culture and Malaysian construction organisations

\section{Introduction}

There is no universally accepted framework which has been established to enable the profession to quantify and analyze safety culture in the Malaysian construction industry. This is one of the challenges faced by Malaysia for not having nor developed any indicators for occupational safety and health as highlighted by Anthony (2005). This research intends to contribute to the development of a framework to operationalise the concept of safety culture in the context of the Malaysian construction industry that will allow safety culture to be uniformly understood and used by all interested parties to inculcate safety culture.

Operationalisation is the process necessary to establish an "operational definition" that will allow a concept or construct 
to be uniformly understood and used by all interested parties (Tustin, 1992). An operational definition assigns meaning to a construct or a variable by specifying the activities or operation necessary to measure it (Kerlinger, 1973). Further, operationally defining a concept to render it measurable is done by looking at the behaviour dimensions, facets, or properties denoted by the concept according to Sekaran (2003). These are then translated into observable and measurable elements so as to develop the measurement of the concept.

The operationalisation of safety culture involves the analysis on various concepts and measures as presented graphically in Figure 1.0.

\section{Literature Review}

\subsection{The Operationalisation}

Operationalisation is valuable if used properly, aiming at establishing ideal structures and offering definitions that approximate the concept included in the research according to Sarantakos (1998, p130). He further states that operationalisation is an indispensable tool of quantitative but its methodological should not be overestimated. The three major elements of operationalisation according to Sarantakos (1998, p130) are;

1) Selection of indicators, which reflect the presence or absence of the element the researcher set out to measure.

2) Quantification of the indicators, identification of the continuum of values the indicators can assume, and assignment of scores that represent the degree of presence

3) Quantification of variables, identification of the continuum of values the indicators can assume, and assignment of scores that represent the degree of presence.

Hence, the approach of this research involved three stages as suggested by Sarantakos (1998); Stage one is the Selection of indicators in which the factors' characteristics are identified. The researcher used the term factors' characteristics to capture the various terms used in safety culture studies, i.e. indicators, dimensions, features, factors, approaches, characteristics etc. which was presented in descriptive form, tabulation (framework) or illustrated as models. This is done by analyzing various model or approaches of safety culture studies. Stage two is the Quantification of indicators, involved the assigning of meaning to the construct by specifying the dimensions and items for each. The third stage is the Quantification of variables, involved the assigning of measurement and scales to the items.

\subsubsection{Stage 1: Selection of indicators}

The selection of indicators involved the identification of the factors' characteristics for safety culture which was based on the review of safety culture models from previous research.

The International Automatic Energy Agency (IAEA) developed a model in 1991 places a greater emphasis on managerial system and structure, indicating that the organisation requires a self-regulating safety management system, to ensure achievement. International Nuclear Safety Advisory Group (INSAG) in this model emphasis on the role of the management system in developing an effective safety culture, as oppose to placing emphasis on the role of individual's and peer group attitude (HSE, 1999).

Geller (1994), following Bandura, proposes the concept of Total Safety Culture, identifying personal characteristics (knowledge, experiences, skills, abilities, intelligence, motivation, personality); behavioural (compliance, coaching, recognition, communication); and environmental (equipment, tools, machines, housekeeping, environment, engineering) factors as key aspects of safety culture.

Cox et. al (1997) further developed a System Model of Safety Culture who also suggests that organisational variables influence the work environment and group processes, and individual behaviour on safety activity. and their actions and commitment as a key group in influencing attitudes, along with structural safety communications systems and employee participation programmes. The general model was broadly supported by empirical research as revealed by HSE (1999).

AEA Technology, between 1993 and 1994, developed another model which focuses on organisational factors as reported by Dalling (1997). Dalling states that the research included;

- A wide ranging technical review of contemporary work of safety culture, organisational and managerial factors, team aspects, individual attitudes and responses and factors influencing cultural change;

- Case histories of safety improvement schemes;

- Studies aimed to determine the factors which correlated with good safety performance, and;

- Initiatives which claimed to improve not only safety but also safety culture itself

Grote and Kunzler (2000) presented a socio-technical model of safety culture that links the safety management system and safety culture to the general organisational design. However the model is schematic and lack of mechanism to improve and assess safety culture. 
Cooper (2000) developed a Reciprocal Safety Culture Model. According to Cooper (2002b), there is no universally accepted model that has yet been established to analyse safety culture. However a psychological conceptual model is available and necessary to reflect upon a wide range of safety-related evidence in the development of the measurement tools. This body of evidence reveals the presence of a dynamic reciprocal relationship between psychological, behavioural and situational factors.

The review of these models also consensus viewed safety culture at the organisational level, in part or as a wholesome. IAEA (1991) and Grote and Kunzler (2000), focus on the management system as the main factors. However AEA Technology (1993-1994) focuses on the organisational and external factors that influence the work environment and group processes whereas Cox et.al, (1997) on the individual behaviour. On the other hand, a combination of three elements; the subjective psychological factors, observable on-going safety-related behaviours and the objective situational features were established by Cooper (2000).

Based on the review, the development of the conceptual operational framework that was adapted in this research is the Reciprocal Safety Culture Model by Cooper (2000) as illustrated in Figure 2.0.This is due to the fact those factors' characteristics which constitutes; the Psychological, Behavioural and the Situational factors allows triangulation of perspectives in the context of safety culture within an organisation. These three elements also mirrored those accidents causation relationship found by a number of researchers (Heinrich et.al, 1980; Weaver, 1971; Reason, 1990; Suraji, 2001). Further, the model itself promote self-regulatory processes consistent to the definition of safety culture in the context of this research as 'The product of shared values, beliefs, attitudes, and patterns of behaviour based on a top-down approach practices that are concerned with minimizing the exposure to conditions considered dangerous or injurious to the entire group members on a self-regulatory basis' (Faridah and Torrance, 2004).

The values, beliefs, attitudes were the psychological factors, the behavioural factors were the pattern of behaviours created and since organisations are contained entities, it should provides an environment that concerned the exposure to conditions considered dangerous which constitutes the situational factors.

\subsubsection{Stage 2: Quantification of indicators}

This stage involved the assigning of meaning to the construct by specifying the dimensions and items for each factors' characteristics.

\subsubsection{The Psychological Dimensions and items}

Schein (1985) states that the value gradually starts a process of cognitive transformation into a belief when the leader proposes a solution based on his belief or on a principle based on facts and the solution works. On the other hand, an attitude lies between the beliefs and the intended behaviour as suggested by Lingard (2002) and Stewart (2002, p.11). In organisations with enduring excellence in safety, the safety values are deeply held and they are brought to the surface in the practices according to Stewart (2002, p.12). Hence, the psychological dimensions measure the values and beliefs as illustrated in Figure 3.0 whereas the observable practices are measured under the behavioural dimensions.

\subsubsection{The Behavioural Dimensions and items}

The identification of the behavioural dimensions was the outcome from the Preliminary Survey. The methodological processes of the Survey and the results were discussed in the Research Methodology section. Five testable factors were identified in the Preliminary Survey, namely Leadership, Organisational Commitment, Management Commitment, Safety Training and Resource Allocation (Faridah and Torrance, 2005). The factors identified from the Preliminary Survey are illustrated in Figure 4.0.

\subsubsection{The Situational Dimensions and Items}

Cooper (1998) considers safety management systems as environmental factors in his model of organisational safety culture. This is due to the fact that organisations are contained entities, where the efficacy of safety management systems is the key internal environmental factor. However since safety culture is the dynamic reciprocal relationship between group member's perceptions and attitudes towards safety (cognition); and there is the presence of external influences including legislation, economics, history and climate (environment or situation). The situational dimensions are categorised as the internal and the external factors as illustrated in Figure 5.0.

\subsubsection{Additional Items for All Dimensions}

The following items do not form a dimension by themselves but were embedded within all the previous dimensions discussed.

\section{Continuous improvement}

The most successful improvement efforts focus on the organisation according to Winchell (1991). Organisationally, according to the author, continuous improvement is a gradual change in how the activities are conducted within the organisation as it is one of the essences of TQM. Continuous improvement means that there is continuous safety 
improvement through the cycle of problem identification and analysis, development and implementation of corrective recommendations, review of results and development of effective controls (Weinstein, 1997). This item was essential to be incorporated as highlighted by Dr. Kazutaka Kogi who is a well-known occupational health specialist and currently a research Adviser of Institute for Science of Labour in Kawasaki of Japan while validating the behavioural factors during his visit at National Institute of Occupational Safety \& Health (NIOSH) Malaysia in March 2004.

\section{Sub-contractors}

Subcontractors are often an integral part of construction projects and have a direct bearing on the company safety (Molenaar, 2002). This is one of the scenarios found in the Malaysian construction organisations (Faridah and Torrance, 2009). The importance of subcontractor's past safety performance as a criterion for soliciting bids for new work will determine the commitment of the Main Contractor towards safety.

\subsubsection{Stage 3: Quantification of variables}

This involved the assigning of measurement and scales to the items. Generally a seven likert- scale were used to measure all the dimensions of the three main constructs as likert scale is widely used in measuring opinions, beliefs and attitudes. Each construct had different number of dimensions which were measured on a 7-point Likert scale. High value of the scale will be consistent with high emphasis on safety culture items being practiced within the organisation and likewise low scale value is consistent with low emphasis on safety culture items.

\section{Research Methodology}

This research uses construction organisations as the unit of analysis. The scope of the study was derived from the whole total population of 866 (overall total of 1,171) numbers of a Grade 7 contractors listed under the Construction Industry Development Board (CIDB) Directory who undertake Building Works within Klang Valley.

However the examination of safety culture is from the individual perspectives of the senior executives as the data source. The approach is consistent with the proposition that the top management is in a position to influence cultural identity, a top-bottom approach as established by IAEA (1991), Cox et.al (1997) and Mohamed (2003).

\subsection{The Preliminary Survey}

The process of sending questionnaires to a total of 866 , took almost a month to administer. This included preparation of cover letters, proof-reading of questionnaires, preparing self addressed envelops, cover letter, typing the addresses of the respondents, coding and franking for postage.

The Preliminary Survey was conducted to identify the management practices that embed safety culture into the organisational culture. This is to capture the behavioural dimensions of the safety culture. The first part of the questionnaire was designed to capture the background of the respondents and the company. These include respondents' personal and safety-related characteristics, their education level, job position and their awareness on the trend to inculcate safety culture. The nature of the projects in which the company had been involved, the techniques and tools utilized within the organisation in relation to project safety. Even though the respondents belong to the same group of Grade 7 contractors, it is important to know the pattern of their involvement and the background of the organisation as culture can arises from the learning experiences as their organisations evolve (Schneider, 1990).

The characteristics of good safety culture practices (Faridah, 2006) form the basis for development of questionnaire. The 24 organisational and safety implementation statements in the second part of the questionnaire were designed to enable responses to identify and add on to a given list, the management practices that facilitate the embedding of safety culture into the organisational culture.

Nonparametric procedures were used to analyze the data obtained from the survey. The nonparametric procedure is a statistical procedure that has certain desirable properties that hold under relatively mild assumptions from which the data was obtained. As an example the use of a survey answers as strongly agree, agree, disagree and strongly disagree are subject to the interpretation of the respondent.

The Statistical Packaging for Social Science (SPSS) version 11.5 was used to perform the data analysis. The initial process was to explore the characteristics of the data. In order to be more objective in the qualitative analysis, a variety of statistical techniques were employed. These techniques were descriptive and inferential. This research used principal components analysis (PCA) to extract the factors. Factor analysis was carried out, which aimed to reduce these large items to several items called factors. Factor analysis is a statistical method used to represent a set of large variables (items or questions) to several factors. Each factor contains the items that are highly correlated among each other.

\subsection{The Main Survey}

The literature review indicates that the present research should include scales dealing with aspects of psychological, behavioral and situational factors' characteristics. The questions were designed to capture these three aspects of safety culture adapted, from Cooper (2000), Stringer (2002), Stewart (2002), and Schein (2004) as the main source of 
references. The operationalisation on the concept of safety culture led to the development of the main questionnaire survey.

\section{Results and Discussion}

The respond rate of the Preliminary Survey was $16.67 \%$. The principal components for extraction method with varimax rotation were used where six factors were extracted. However, the sixth factor was excluded since it contains only 1 item. Thus, only five items were considered and defined as follows:

Factor 1 (5 items): Leadership

Factor 2 (3 items): Safety Training

Factor 3 ( 2 items): Organisational Commitment

Factor 4 ( 2 items): Management Commitment

Factor 5 ( 2 items): Resource allocation

Sample of items for each factors are presented in Table 1.0 in Appendix 1.

As illustrated in this table, it can be clearly seen that factor 1 comprises of five items and their respective factor loadings range from 0.625 to 0.751 . The Cronbach's Alpha for these items was 0.8456 . Factor 2 was made up of only two items with factor loadings ranging from 0.642 to 0.736 while Factor 3, Factor 4 and Factor 5 comprise of two items with factor loadings ranging from 0.761 to $0.868,0.759$ to 0.826 and 0.626 to 0.688 respectively. The coefficient of reliability for Factor 3 was 0.7901 while for Factor 4 was 0.5966 . However, for Factor 5 its coefficient of reliability was relatively low (0.1576). The five factors extracted can explain $59.61 \%$ of the total (standardized) sample variance. The five factors identified are consistent with the literature review on the "good" safety culture features (Faridah and Torrance, 2005).

The psychological covers the aspects of values and beliefs since safety culture itself are a cognitive construct. Four items were used to measure the dimension namely; personal emphasis given for safety as compared to quality, cost efficiency and production volume; perception towards senior managers on the same items, the belief that injuries can be prevented and the belief that excellent in safety will affect excellence in other areas.

The behavioural constructs comprised of factors identified via the Preliminary Survey namely; leadership; organisational commitment; management commitment; training and resource allocation. Seven items were used to measure on leadership, management commitment, safety training and resource allocation. However for organisational commitment which was further sub-divided into Strategy and Structure were measured with seven and five items respectively.

On the other hand the situational constructs consist of the internal i.e the safety management system of the organisation and the external factors influencing the organisations i.e the industry norms, legislation and regulation, economic climate, individual background, organisational history and the sub-contractors' background. Sample items for each dimension are presented in Appendix 11.

As mention earlier, the measurement and scale constitutes the third stage of the operationalisation. Generally a seven likert- scale were used to measure all the dimensions of the three main constructs as likert scale is widely used in measuring opinions, beliefs and attitudes. Each construct had different number of dimensions which were measured on a 7-point Likert scale.

Cooper (2000) highlighted the three context; safety climate; behavioural and the safety management dimensions separately, specifying the items and applying three different research methods. However in the context of this research, the examination of safety culture is from the individual perspectives of the senior executives as the data source. The approach is consistent with the proposition that the top management is in a position to influence cultural identity, a top-bottom approach as established by IAEA (1991), Cox et.al (1997) and Mohamed (2003).

The operationalisation of the concept of safety culture involved the choice of sequencing the research methods. Preliminary Survey was carried out to identify the factors or practices that embed safety culture into the organisational culture. The factors identified which are behavioural in nature were expanded further to include the aspects of psychological and situational factors formulated into the Main Survey which forms the measurement scale for safety culture. While safety management system reflects the competence of the organisation to manage safety, safety culture reflects the actual commitment throughout the organisation (Eurocontrol, 2005).

\section{Conclusion}

This paper set out the elements involved for the operationalisation of safety culture. The approach involved three stages as suggested by Sarantakos (1998); Stage one is the Selection of indicators in which the factors' characteristics are identified. This is done by analyzing various model or approaches of safety culture studies. Stage two is the 
Quantification of indicators, involved the assigning of meaning to the construct by specifying the dimensions and items for each. The third stage is the Quantification of variables, involved the assigning of measurement and scales to the items.

The operationalisation of safety culture for the Malaysian construction organisations for this research adopted Coopers' Safety Culture Model which is based on the psychological, behavioural and situational factors' characteristics. The psychological factors incorporate the values, beliefs and attitudes as the dimensions. The behavioural factors were measured by the leadership, the organisational commitment, the management commitment, training and the resource allocation. The dimensions for situational factors were divided into two distinct categories; the internal and the external factors. The internal measures the safety management system whereas the external was measured by the factors such as government regulations; economic conditions, competitive industry forces, and changing technology create pressure on organisations and their managers.

The process of operationalisation allows the concept of safety culture to be uniformly understood and used by interested parties. The related study on specific factors' characteristics of safety culture has not been covered by any researchers in Malaysia and, therefore, will contribute to its development in future.

\section{Acknowledgement}

The paper is part of a PhD thesis (safety culture) supervised by the late Emeritus Professor Dr. Johan Victor Brownlie Torrance Abdullah of UiTM. Special thanks also go to the reviewers for their invaluable comments on this paper.

\section{References}

Anthony, L. (2005). Occupational Health Challenges in Malaysia. NCD Malaysia, 4(1).

Beaumont, R. (2000, 13/04/2000). Research Methods \& Experimental Design: A set of notes suitable for seminar use.

Cooper, M.D. (1998). Improving Safety Culture, John Wiley \& Sons.

Cooper, M. D. (2000). Towards a Model of Safety Culture. Safety Science, 36, 111-136.

Cox, S., Chyne, A,. and Alexander, A. (1997). Safety culture in offshore environments: developing the safety climate measurement tool. In HSE (1999) Development of a Business Excellence Model of Safety Culture. London.

Dalling, I. (1997). Understanding and assessing safety culture. Radiological Protection, 17(4), 261-274.

Eurocontrol. (2005). Understanding Safety Culture in Air Traffic Management. European Organization for the Safety of Air Navigation Project D16/2005.

Faridah Ismail., and Torrance, J.V. (2004). Literature review on defining safety culture. The Malaysian Surveyor, (39.2), 33-37.

Faridah Ismail., and Torrance, J.V. (2005). A Study on Safety Culture of the Malaysian Construction Organisation in Klang Valley. Selangor, Institution of Research Development and Commercialisation,Universiti Teknologi MARA.

Faridah Ismail., and Torrance, J.V. (2009). A Framework of Safety Culture for the Malaysian Construction Organisations. Institute of Graduate Studies. Selangor, Universiti Teknologi MARA. PhD: 366.

Geller, S. E. (1994). Ten principles for achieving a total safety culture. Professional Safety, (September), 18-24.

Grote, G., Kunzler, C. (2000). Diagnosis of safety culture in safety management audits. Safety Science, 34, 131-150.

Heinrich, H. W., Peterson D. \& Roos N. (1980). Industrial Accident Prevention. New York, McGraw-Hill.

HSE. (1999). Development of a Business Excellence Model of Safety Culture. London.

IAEA. (1991). Safety Culture: A report by the International Nuclear Safety Advisory Group. Safety Series No.75-INSAG-4. Vienna.

Kerlinger, F. N. (1973). Foundation of Behavioural Research_New York, Holt, Renehart and Winston

Lingard, H. (2002). The effect of first aid training on Australian construction workers' occupational health and safety knowledge and motivation to avoid work-related injury or illness. Construction Management and Economics, 20, 263-273.

Mohamed, S. (2003). Scorecard approach to benchmarking organizational safety culture in construction. Construction Engineering and Management, (January/February), 80-88.

Molenaar, K., Brown, H., Caile, S., and Smith, R. (2002). Corporate Culture: A study of firms with outstanding construction safety. Professional Safety.

Reason, J. (1990). Human Error. Cambridge, Cambridge University Press.

Sarantakos, S. (1998). Social Research. New York, Palgrave. 
Sekaran, U. (2003). Research Methods for Business. United States of America, John Wiley \& Sons, Inc.

Schneider, B. (1990). Organizational Climate And Culture. California, Jossey- Bass.

Schein, E. H. (1985). Organizational Culture and Leadership. San Fransisco, Jossey-Bass.

Schein, E. H. (2004). Organizational Culture and Leadership. United States of America, Jossey - Bass.

Suraji, A., and Duff et al. (2001). Development of casual model of construction accident causation. Journal of Construction Engineering and Management, 127(4), 337-344.

Stewart, J. M. (2002). Managing for World Class Safety. Canada, John Wiley \& Sons.

Stringer, R. (2002). Leadership and Organizational Climate, Prentice Hall

Tustin, C. O. (1992). The Operationalisation of Service Quality Using Quality Dimensions and Expectation/ Perception Gap Analysis. Arizona State University. PhD: 275.

Weaver, D. (1971). Symptoms of operational error. Professional Safety (Oct): ASSE.

Weinstein, B.W. (1997). Total Quality Safety Management and Auditing. New York, Lewis Publisher.

Winchell, W. (1991). Continuous Quality Improvement: A Manufacturing Professional's Guide. In. 


\section{Appendix 1. Questionnaire items in Preliminary Survey}

Table 1. Summary of the result of factor analysis

\begin{tabular}{|c|c|c|c|c|}
\hline Factors & & Items & $\begin{array}{c}\text { Factor } \\
\text { Loadings }\end{array}$ & $\begin{array}{c}\text { Cronbach's } \\
\text { Alpha }\end{array}$ \\
\hline 1 & $\begin{array}{l}\text { 3) } \\
\text { 4) }\end{array}$ & $\begin{array}{l}\text { All employees feel confident enough in the } \\
\text { organisational management to be able to } \\
\text { voice their safety concerns. } \\
\text { All levels of management actively participate } \\
\text { in all safety training programmes and safety } \\
\text { committees. } \\
\text { Safety remains a priority even when other } \\
\text { organisational demands arise. } \\
\text { Organisational management clearly state } \\
\text { long-term objectives and plans for safety. } \\
\text { Safety is a component of organisational } \\
\text { strategic planning. }\end{array}$ & $\begin{array}{l}0.730 \\
0.642\end{array}$ & 0.8456 \\
\hline 2 & 1) & $\begin{array}{l}\text { All new employees should receive a thorough } \\
\text { orientation of the organisational safety. } \\
\text { Safely is shared value within the } \\
\text { organisation. } \\
\text { The organisation should provide a mentoring } \\
\text { program for all new employees to develop } \\
\text { safe working habits. }\end{array}$ & $\begin{array}{l}0.736 \\
0.645 \\
0.642\end{array}$ & 0.6692 \\
\hline 3 & $\begin{array}{l}\text { 1) } \\
\text { 2) }\end{array}$ & $\begin{array}{l}\text { Safety is part of the organisation statement. } \\
\text { Occupational safety \& health is part of the } \\
\text { organisational culture. }\end{array}$ & $\begin{array}{l}0.868 \\
0.761\end{array}$ & 0.7901 \\
\hline 4 & 2) & $\begin{array}{l}\text { The organisation tries to fix the problem } \\
\text { related to safety rather than fix the blame. } \\
\text { If an accident occurs, the organisational } \\
\text { leaders try to find the root cause. }\end{array}$ & $\begin{array}{l}0.826 \\
0.759\end{array}$ & 0.5966 \\
\hline 5 & 2) & $\begin{array}{l}\text { The safety department is considered an } \\
\text { organisational expense centre. } \\
\text { 2) All members of the organisation can } \\
\text { contribute safety items for consideration to } \\
\text { the budgetary committee. }\end{array}$ & 0.626 & 0.1576 \\
\hline
\end{tabular}




\section{Appendix 2. Questionnaire items in the Main Survey}

The respondents were asked to endorse the statements using a seven-point Likert-type scale (from 1=very high emphasis to $7=$ very low emphasis).

PSYCHOLOGICAL: Culture is a cognitive construct. This section measures the value of safety in your company

\section{Your Values \& Beliefs}

a. Indicate the emphasis you personally give to the following items

Quality towards customer focus

Cost efficiency

Production volume

\section{Safety}

b. Indicate where you think the senior managers in your organisation emphasis the same items

Quality towards customer focus

\section{Cost efficiency}

Production volume

\section{Safety}

c. Your belief that injuries can be prevented

d. Indicate your belief that a drive (strong, long-term effort) for excellence in safety would affect the ability to achieve excellence in other areas: productivity etc

BEHAVIOURAL: This section measures the behaviour - based safety practices in your company.

\section{Leadership:}

a. The Senior Manager are role model

b. Senior Manager are visible at worksites

c. Senior Manager is supportive and helpful to subordinates in their day-to-day activities.

d. Senior Manager involves people in setting their goals

e. The Senior Manager encourage the subordinates to participate in making decisions

f. The Senior Manager provide leadership for OSH activities in the organisation

g. Senior Manager owes the overall responsibility for the sub-contractors' safety \& health

h. Others (Please specify)

\section{ii Organisational Commitment}

\section{Strategy}

a. The safety policy statement describes the organisation's core beliefs, commitments, and responsibilities regarding safety, and connects these successes to the success of the organisation's overall mission.

b. The organisation clearly stated safety in long-term objectives and plans for the organisation

c. The organisational objectives state that safety is paramount within the organisation

d. This organisation provide clear and specific safety budgets

e. The safety policy statement defines and reinforces the safety objective expressed in the mission statement

f. Safety policies and objectives are consistently reviewed and remain timely

g. Sub-contractors past safety performance is an important criteria for selection in the organisation.

h. Others (please specify)

\section{Structure}

a. The organisation established clear, specific performance goals for subordinate's job

b. Structures of the organisation are established to define and communicate to members of the organisation the responsibility, accountability and authority of persons who identify, evaluate or control hazards and risk

c. Structures and process are established to ensure that OSH is a line-management responsibility which is known and accepted at all levels 
d. Structures and process are reviewed timely for OSH excellent

e. Structures and process are established to provide effective supervision of the sub-contractors' work

f. Others (Please specify)

\section{iii Management Commitment :}

a. The top management acts as chairman or member of safety committees

b. The top management administers safety policies

c. The top management participates in decision making on all activities that give an impact on safety matters

d. The top management regularly audit safety systems to provide information feedback with a view to developing ideas for continuous improvement The top management have mechanisms in place to gather safety related information, measure safety performance, and bring people together to learn

e. necessary action

The top management thoroughly examine safety reports, investigating all accidents, near misses and takes

f. The top management monitor the safety management system of all the sub-contractors

g. Others (please specify)

iv Safety Training:

a. The necessary OSH competence requirements; arrangement established and maintained to ensure that all persons are competent to carry out safety and health aspects of their duties and responsibilities

b. $\quad$ Safety training are provided to all subordinates free of charge

c. The safety training programmes are provided effectively, timely initial and refresher training at appropriate intervals

d. Everyone is trained regularly and thoroughly in specific job techniques and in more general practices.

e. There is a mentoring program for all new employees to develop safe working habits

f. The training programmes are reviewed regularly to ensure their relevance and effectiveness.

g. Safety training background is a criteria for sub-contractors' to receive invitation for new works in this organisation.

h. Others (Please specify)

\section{v Resource Allocation :}

a. There is a reward system (compensation, recognition, promotion) that is directly related to performance rather than to personal relationships and so on.

b. Good performance is recognised more often then critizing for poor performance.

c. Recognition, praise and similar methods are rewarded for good performance.

d. Appreciation given when people put extra time and effort on safety

e. Sufficient resources are reviewed timely for safety purposes

f. The safety department is considered an organisational expense centre.

g. An incentive is offered to sub-contractors to become excellent safety performers

h. Others (please specify) 


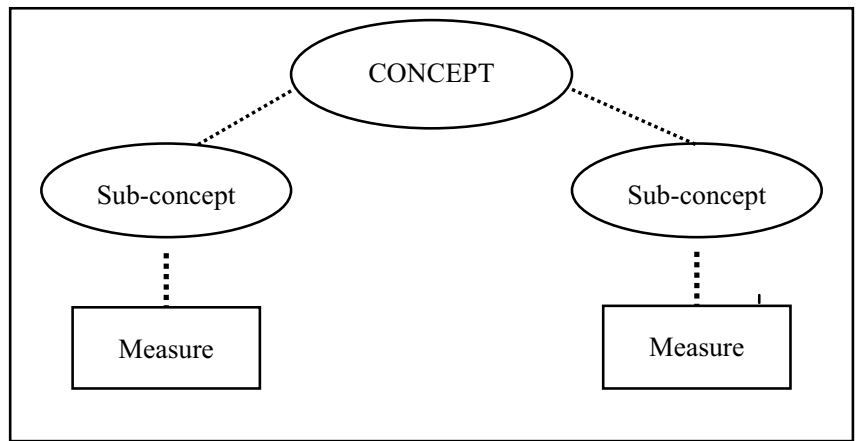

Figure 1. Graphical Method of Presenting

Operationalisation

Source: Adapted from Beaumont (2000)

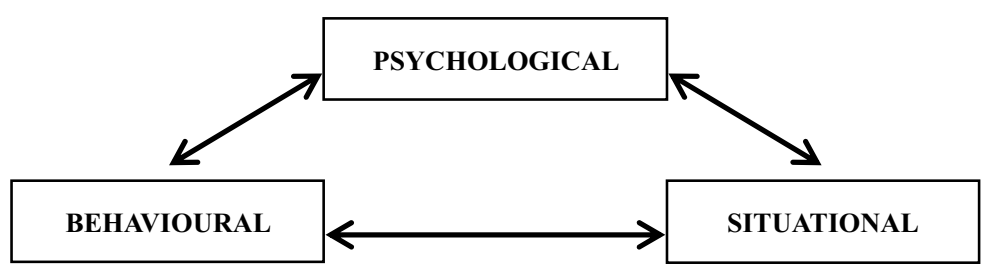

Figure 2. Factors' Characteristics of Safety Culture

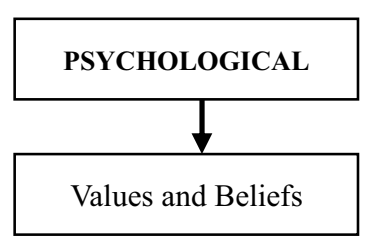

Figure 3. The Psychological Dimensions 


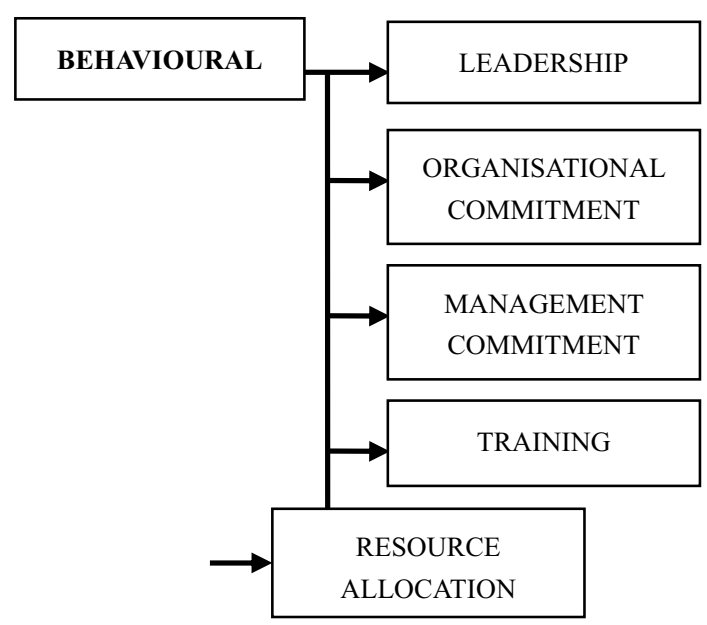

Figure 4. The Behavioural Dimensions

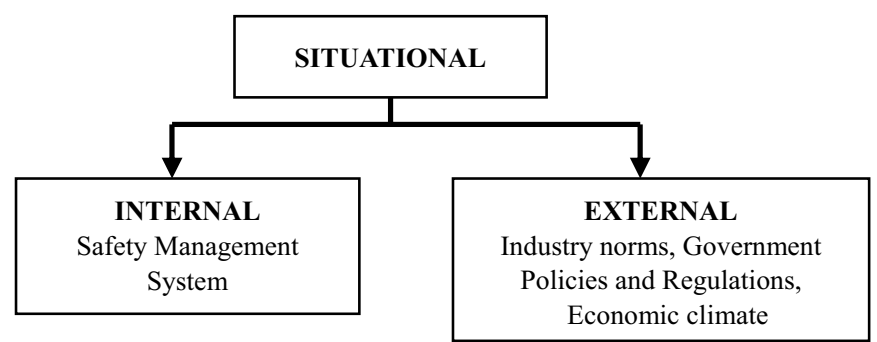

Figure 5. The Situational Dimensions 